\title{
INFECÇÃO PUERPERAL E MORTALIDADE MATERNA
}

\section{ARTIGO DE REVISÃo}

SANTOS, Keily dos ${ }^{1}$

BATISTA, Marcos Antonio Silva ${ }^{2}$

PAULA, Michelly Rodrigues de ${ }^{3}$

GONÇALVES, Rosane Cristina Mendes 4

REIS, Suely da Silva ${ }^{5}$

SANTOS, Keily dos. Et al. Infecção puerperal e mortalidade materna. Revista Científica Multidisciplinar Núcleo do Conhecimento. Ano 05, Ed. 12, Vol. 01, pp. 98 110. Dezembro de 2020. ISSN: 2448-0959, Link de acesso:https://www.nucleodoconhecimento.com.br/sem-categoria/infeccao-puerperal

\section{RESUMO}

Infecção puerperal é definida como sendo qualquer infecção bacteriana do trato genital feminino no pós-parto recente. Mortalidade materna é o óbito da mulher durante a gestação ou dentro de um período de 42 dias após o término da gravidez. Trata-se de uma revisão bibliográfica com o tema "Infecção puerperal e mortalidade materna - uma revisão de literatura", abrangendo suas particularidades e adjacências. Foram consultadas as seguintes bases eletrônicas de dados: Literatura LatinoAmericana e do Caribe em Ciências da Saúde (LILACS), SCIELO e Google

\footnotetext{
${ }^{1}$ Graduada em Enfermagem pelo Centro Universitário Luterano de Palmas.

2 Especialista em Enfermagem do Trabalho pela Faculdade Gianna Bereta.

${ }^{3}$ Graduada em Enfermagem pelo Centro Universitário Luterano de Palmas.

${ }^{4}$ Especialista em Saúde Pública pela Universidade Federal do Tocantins - UFT.

${ }^{5}$ Graduada em Enfermagem pelo Centro Universitário Luterano de Palmas.
} 
Acadêmico. O objetivo do estudo foi discutir a infecção puerperal enquanto causa da mortalidade materna. Foram encontradas 55 publicações e efetivamente utilizadas 17 neste trabalho, as quais foram publicadas entre os anos de 2006 - 2014. Os achados descritos indicam a necessidade de haver transformações que abranjam a efetividade do planejamento familiar, assistência pré-natal adequada, segundo preconiza a Organização Mundial da Saúde, bem como redução do número de cesarianas como forma de evitar complicações pós-parto dentre elas infecção puerperal que é a segunda causa de mortalidade materna. As transformações devem ir além das ações de saúde envolvendo maior eficiência pelos órgãos executores das políticas de saúde no sentido de melhorar o monitoramento das ações visto somente cerca da metade dos casos notificados são investigados, também há deficiências relacionadas às subnotificações, sendo importante ainda fomentar a atuação do enfermeiro no sentido de evitar, controlar e reduzir as infecções puerperais, reduzindo assim os índices de mortalidade materna. Sugere-se intensificação no monitoramento e avaliação por parte dos órgãos responsáveis como Ministério da Saúde e Secretarias de Estado e Municipais e Comitês de Mortalidade Materna, frente à investigação das notificações, bem como a busca pela redução da subnotificação.

Palavras-chaves: Infecção puerperal, mortalidade materna, saúde da mulher.

\section{INTRODUÇÃO}

Morte materna é a morte de uma mulher durante a gestação ou até 42 dias após o término da gestação, independentemente da duração ou da localização da gravidez. É causada por qualquer fator relacionado ou agravado pela gravidez ou por medidas tomadas em relação a ela. Não é considerada morte materna a que é provocada por fatores acidentais ou incidentais (BRASIL, 2007).

A redução da mortalidade materna no Brasil é ainda um desafio para os serviços de saúde e a sociedade como um todo. As altas taxas encontradas se configuram como uma violação dos direitos humanos de mulheres e crianças e um grave problema de saúde pública, atingindo desigualmente as regiões brasileiras com maior prevalência 
entre mulheres e crianças das classes sociais com menor ingresso e acesso aos bens sociais (BRASIL, 2007).

A partir de análises das condições relacionadas à mortalidade materna, pode-se avaliar o grau de desenvolvimento de uma determinada sociedade. Uma elevada Razão de Mortalidade Materna (RMM) é indicativa de precárias condições socioeconômicas, baixo grau de informação e escolaridade, dinâmicas familiares em que a violência está presente e, sobretudo, dificuldades de acesso a serviços de saúde de boa qualidade (BRASIL, 2011).

Dentre as principais causas de mortalidade materna destaca-se a infecção puerperal, visto que, atualmente, apesar do avanço científico e tecnológico nas diversas áreas do conhecimento, a infecção puerperal constitui, ainda, grande problema pela sua prevalência, morbidade e, até mesmo, letalidade (GUIMARÃES; CHIANCA; OLIVEIRA, 2007).

A infecção puerperal está relacionada com as infecções da assistência em saúde, sendo uma complicação do período gravídico-puerperal e contribui para o aumento da morbimortalidade materna. Assim, a infecção puerperal é compreendida como qualquer infecção bacteriana do trato genital feminino concorrente ao processo do parto e nascimento (FILHO et.al, 2010).

O presente estudo desenvolveu-se a partir da discussão acerca da relação entre infecção puerperal e morte materna, apesar do avanço científico e tecnológico nas diversas áreas do conhecimento, a infecção puerperal constitui, ainda, um grande problema de saúde pública, evidenciado pela sua alta prevalência de morbidade e letalidade.

\section{REFERENCIAL TEÓRICO}

\subsection{INFECÇÃO HOSPITALAR}

O conceito de Infecção Hospitalar é compreendido como aquela infecção adquirida após a admissão do paciente e que se manifeste durante a internação ou após a alta, 
quando puder ser relacionada com a internação ou procedimentos hospitalares. Atualmente, o termo infecção relacionada a serviços de saúde é mais adequado (GOIS K. F. Et al 2012).

O surgimento do ambiente hospitalar data aproximadamente de 330 A.C., quando o primeiro hospital urbano foi instalado no Império Romano. Neste período o hospital era tido como uma aglomeração de doenças. Quem tinha condição de se tratar, faziao em seu domicílio. Os necessitados então estariam sujeitos à contaminação e infecção pela deficiência na assistência (OLIVEIRA, MARUYAMA; 2008).

Referente ao Controle de Infecção acredita-se que só será possível se compuser a formação do profissional com a compreensão de que se constituem em uma só prática, pois realizar um procedimento significaria adotar as medidas preventivas pertinentes (AZAMBUJA; PIRES; VAZ, 2004).

\subsection{CAUSAS DE INFECÇÃO PUERPERAL}

Entre os principais fatores de risco estão a amniorrexe e/ou trabalho de parto prolongado, manipulação vaginal excessiva (toques), más condições de assepsia, debilidade imunológica, desnutrição, obesidade, trauma cirúrgico, operação cesariana e retenção de restos ovulares (CRUZ, 2013).

No que se refere à influência dos partos, independente da sua natureza, é possível observar em várias instituições obstétricas que não se tem adotado a filosofia e as rotinas e condutas recomendadas pelo Ministério da Saúde para a humanização, desta forma, a assistência ao parto envolve grande número de intervenções que podem influenciar o aumento das infecções (NOMURA; ZUGAIB, 2004).

Segundo Duarte, Chrisostimo e Christovam (2014) infecção puerperal está diretamente relacionada à assistência prestada nos serviços de saúde, sendo assim, torna-se como prioridade o controle às infecções adquiridas em ambiente hospitalar. Agregando ainda às causas da infecção puerperal, temos a falta de vigilância após a alta, à alta precoce das puérperas e o retorno da paciente fora da instituição onde ocorreu o parto, além de fatores ambientais, individuais e materiais. 


\subsection{MORTALIDADE MATERNA}

Os estudos conduzidos por Soares et al (2012), conclui que apesar dos altos índices apresentados, a maioria dos óbitos poderiam ser evitada se as condições de saúde locais fossem semelhantes àquelas dos países desenvolvidos, com acesso a serviços de referência de qualidade.

O uso do indicativo de Razões de Mortalidade Materna (RMM), que está relacionado a precárias condições socioeconômicas, baixo grau de informação e escolaridade, dinâmicas familiares onde à violência está presente e, sobretudo, considerando ainda as dificuldades de acesso a serviços de saúde qualificados em suas assistências (BRASIL, 2011).

Pela definição, o conjunto de mortes maternas (ou obstétricas) pode ser subdividido e classificado em mortes obstétricas diretas e indiretas. As primeiras são aquelas por complicações de causas ou estados que só ocorrem no ciclo gravídico-puerperal, como desprendimento prematuro de placenta. As mortes maternas indiretas são aquelas resultantes de doenças pré-existentes ou que se desenvolvem durante a gravidez, não decorrentes de causas obstétricas diretas, mas que foram agravadas pelo efeito fisiológico da gravidez como a hipertensão arterial sistêmica (NASCIMENTO et al., 2007).

\subsection{SAÚDE DA MULHER}

A saúde da mulher deve ser compreendida dentro das estratégias para o desenho de práticas mais eficazes. Essas práticas devem ser construídas no cotidiano da atenção à saúde tornando-se imperativo o trabalho interdisciplinar e uma compreensão ampliada dos determinantes do processo saúde-doença (COELHO et al., 2009).

As demandas em saúde da mulher apresentam-se complexas. O ciclo vital feminino é marcado por eventos biológicos e sociais que, por vezes, interagem e determinam alterações no processo saúde-doença. O profissional de saúde, necessita desenvolver um olhar integral para com a mulher, considerando, sobretudo, a 
presença e influência de elementos subjetivos em sua relação com o mundo, com a sociedade, com a família e consigo mesma (FALCÃO; VIANA; NOVAES, 2011).

A atenção no puerpério não está consolidada nos serviços de saúde. A grande maioria das mulheres retorna ao serviço de saúde no primeiro mês após o parto. Entretanto, sua principal preocupação, assim como a dos profissionais de saúde, é com a avaliação e vacinação do recém-nascido. Isso pode indicar que as mulheres não recebem informações suficientes para compreender a importância da consulta puerperal (GOMES; NEVES, 2011).

A humanização deve estar associada à qualidade de atenção em todos os níveis de saúde, sendo uma condição essencial para que as ações de saúde auxiliem na resolução dos problemas identificados, na satisfação das usuárias, em especial no fortalecimento da capacidade das mulheres frente à identificação de suas demandas, também no reconhecimento e reivindicação de seus direitos e na promoção do autocuidado (BRASIL, 2011).

\section{METODOLOGIA}

Trata-se de uma revisão literária com a temática Infecção puerperal, abrangendo suas particularidades e adjacências, baseado em leituras estruturadas, obtidas através da realização de uma pesquisa de artigos científicos nas bases de dados da Literatura Latino-Americana e do Caribe em Ciências da Saúde (LILACS), SCIELO e Google Acadêmico.

Para a seleção dos estudos foi utilizado o critério de terem sido publicados na literatura nacional e por possuírem em seu título ou resumo os descritores: infecção puerperal e mortalidade materna.

A seleção do material ocorreu nos meses de fevereiro e março do ano de 2015. Foram encontradas 55 publicações e efetivamente utilizadas 17 neste trabalho, as quais foram publicadas entre os anos de 2006 - 2014 (Tabela 01). 
TABELA 01 - Artigos e autores utilizados para esta pesquisa, distribuídos em ordem cronológica decrescente:

\begin{tabular}{|c|c|c|c|}
\hline Revista & Artigo & Autor & Ano \\
\hline $\begin{array}{lr}\text { Revista } & \text { de } \\
\text { Enfermagem } & \text { UFPE } \\
\text { on line. } & \end{array}$ & $\begin{array}{l}\text { Atuação do enfermeiro no } \\
\text { controle de infecção puerperal: } \\
\text { revisão integrativa }\end{array}$ & $\begin{array}{l}\text { Duarte, M. R. } \\
\text { et. al. }\end{array}$ & 2014 \\
\hline $\begin{array}{l}\text { Caderno de } \text { Saúde } \\
\text { Pública, Rio de } \\
\text { Janeiro }\end{array}$ & $\begin{array}{l}\text { Estimação da razão de } \\
\text { mortalidade materna no Brasil, } \\
2008-2011\end{array}$ & $\begin{array}{l}\text { Szwarcwald C. } \\
\text { L. et. al. }\end{array}$ & 2014 \\
\hline $\begin{array}{l}\text { Revista Eletrônica } \\
\text { Trimestral de } \\
\text { Enfermagem }\end{array}$ & $\begin{array}{l}\text { Infecção de ferida operatória } \\
\text { após cesariana em um hospital } \\
\text { público de Fortaleza }\end{array}$ & Cruz, L.A. & 2013 \\
\hline $\begin{array}{l}\text { Revista Brasileira de } \\
\text { Ginecologia } \\
\text { Obstétrica. }\end{array}$ & $\begin{array}{l}\text { Mortalidade materna e } \\
\text { desenvolvimento: a transição } \\
\text { obstétrica no Brasil }\end{array}$ & Souza, J. P. & 2013 \\
\hline $\begin{array}{l}\text { Revista Brasileira de } \\
\text { Ginecologia } \\
\text { Obstétrica. }\end{array}$ & $\begin{array}{l}\text { Mortalidade materna em um } \\
\text { centro de referência do Sudeste } \\
\text { Brasileiro }\end{array}$ & $\begin{array}{l}\text { Troncon J.K, et. } \\
\text { al. }\end{array}$ & 2013 \\
\hline $\begin{array}{l}\text { Anais do Congresso } \\
\text { Brasileiro de } \\
\text { Enfermagem } \\
\text { Neonatal }\end{array}$ & $\begin{array}{l}\text { Infecção puerperal em uma } \\
\text { maternidade de referência de } \\
\text { Teresina-PI }\end{array}$ & $\begin{array}{l}\text { Gois, K. F. et } \\
\text { al. }\end{array}$ & 2012 \\
\hline
\end{tabular}


Revista Brasileira de Ginecologia

Obstétrica.

Revista Baiana de Saúde Pública

Com. Ciências Saúde

Caderno

Saúde

Pública

Saúde Infantil

Revista de Medicina de Minas Gerais
Causas de mortalidade materna segundo níveis de complexidade hospitalar

Soares, V. M. N 2012 et al.

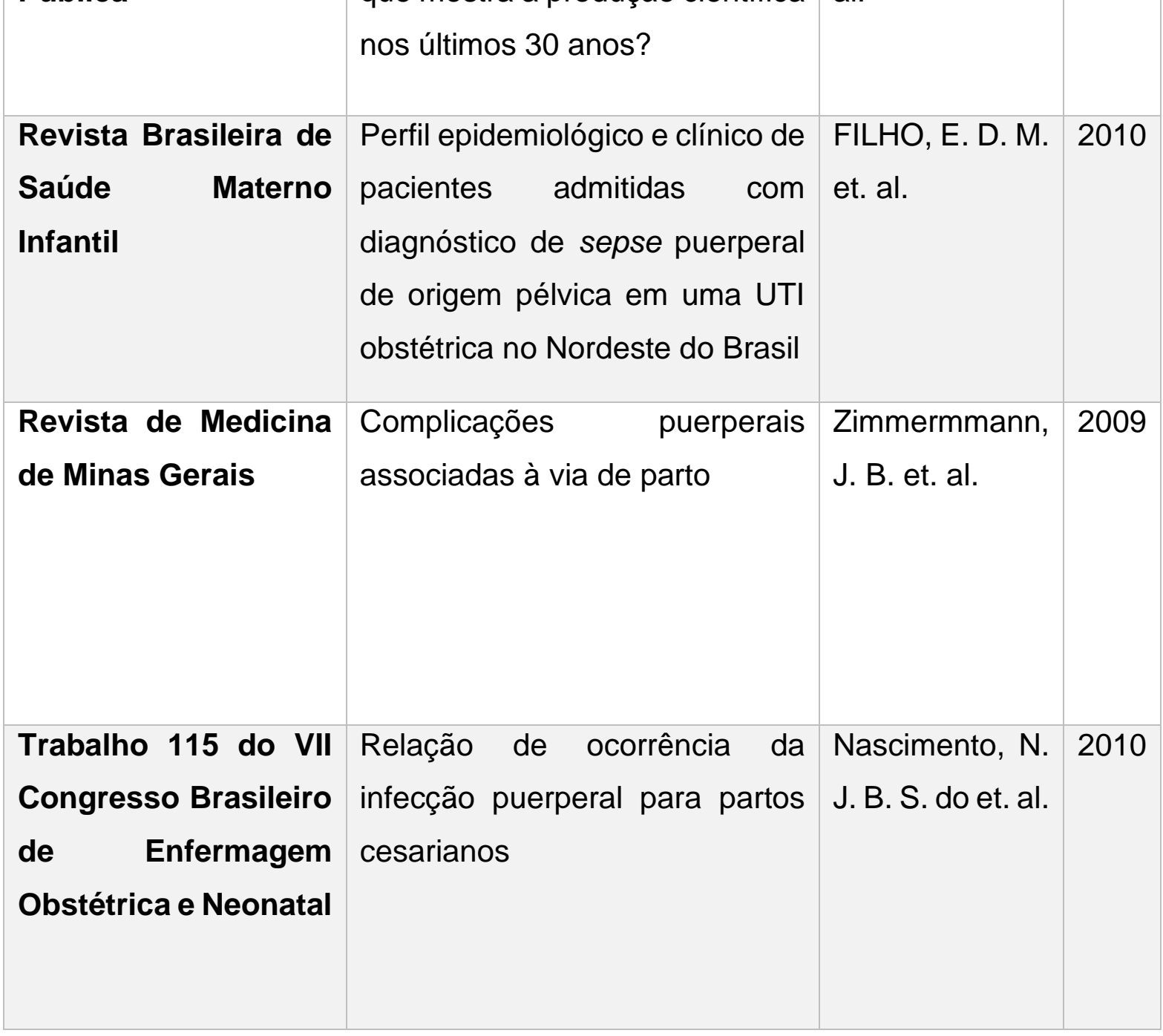




\begin{tabular}{|c|c|c|c|}
\hline Revista da Sociedade & Choque séptico puerperal por & Araújo, S. de A, & 2009 \\
\hline $\begin{array}{l}\text { Brasileira de } \\
\text { Medicina Tropical }\end{array}$ & $\begin{array}{l}\text { Streptococcus } \beta \text {-hemolítico e } \\
\text { síndrome de Waterhouse- } \\
\text { Friderichsen }\end{array}$ & et. al. & \\
\hline $\begin{array}{lr}\text { Revista } & \text { Latino- } \\
\text { americana } & \text { de } \\
\text { Enfermagem } & \end{array}$ & $\begin{array}{l}\text { Infecção puerperal sob a ótica } \\
\text { da assistência humanizada ao } \\
\text { Parto em maternidade pública }\end{array}$ & $\begin{array}{l}\text { Guimarães E. } \\
\text { E. R. Chianca } \\
\text { T. C. M. } \\
\text { Oliveira A. C. }\end{array}$ & 2007 \\
\hline Saúde Coletiva & $\begin{array}{l}\text { Ocorrência de Infecção } \\
\text { Puerperal em um Hospital } \\
\text { Universitário de Cuiabá }\end{array}$ & $\begin{array}{l}\text { Toledo, A. L. P. } \\
\text { Silveira, C. S. }\end{array}$ & 2006 \\
\hline $\begin{array}{l}\text { Revista Brasileira } \\
\text { Ginecológica } \\
\text { Obstétrica. }\end{array}$ & $\begin{array}{l}\text { Intervenções benéficas no pré- } \\
\text { natal para prevenção da } \\
\text { mortalidade materna }\end{array}$ & $\begin{array}{l}\text { Calderon I. de } \\
\text { M. P., Cecatti J. } \\
\text { G., Vega C. E. } \\
\text { P. }\end{array}$ & 2006 \\
\hline
\end{tabular}

FONTE: Dados coletados pelos autores.

\section{RESULTADOS E DISCUSSÕES}

\subsection{ANÁlise DA LITERATURA SOBRE INFECÇÃO PUERPERAL ASSOCIADA À MORTALIDADE MATERNA}

Referente ao puerpério deve-se adotar uma postura de maior atenção nesse período, pois mesmo havendo técnicas avançadas e cuidados de higienização por parte dos profissionais de saúde nas fases de pré, intra e pós-operatórios o número de mulheres que evoluem para infecção no sítio cirúrgico pós-cesárea ainda é considerável, sendo ainda são elevadas as taxas de infecções hospitalares (CRUZ et al, 2013). 
A atuação do enfermeiro frente ao controle de infecção puerperal deve ser estabelecida de modo prático e objetivo. E emerge a necessidade de transformar o modelo de assistência à puérpera em todas as etapas do ciclo grávido puerperal, desde a consciência do profissional até os seus direitos de assistência integral, visto que a atuação do enfermeiro é diretamente legal e de extrema importância no cuidado prestado (DUARTE et al, 2014).

Os achados de Martins Filho, et. al (2010) apontam para a taxa de infecção puerperal mais elevadas após cesarianas quando comparados aos partos normais. Isso corrobora com o apontamento dos estudos de Guimarães; Chianca; e Oliveira (2007) onde a cesariana também se comporta como fator de risco para a infecção puerperal.

\subsubsection{INFECÇÃO PUERPERAL}

Em estudo realizado em uma maternidade pública de Teresina-PI, utilizando-se todos os prontuários encontrados de mulheres que foram admitidas no período de janeiro de 2008 a dezembro de 2010 com diagnóstico de infecção puerperal, verificou-se que das 49.546 internações ocorridas entre 2008 e 2010, 244 (4,6\%) tinham o diagnóstico de infecção puerperal. A frequência de infecção dos três anos analisados foi mais elevada no ano de 2009 (48,1\%). O resultado final apresenta uma incidência de 4,6\% de mulheres com diagnóstico de infecção puerperal (GOIS et al, 2012).

Toledo e Silveira (2006) em seu estudo desenvolvido no Hospital Geral Universitário de Cuiabá - MT, onde foram analisadas 20 pacientes com infecção puerperal conforme dados como: idade; tempo de internação, realização de pré-natal e tipo de parto. Os resultados apontam que 80\% tinham idade inferior a 25 anos; $70 \%$ ficaram mais de 48 horas internadas, $75 \%$ responderam que realizaram pré-natal, $90 \%$ tiveram cesárea.

A literatura realça que a incidência de cesarianas tem aumentado à medida que se eleva o padrão social das gestantes, não havendo correspondência com o risco obstétrico. (ZIMMERMMANN et al., 2009). 
Araújo et al (2009) afirmam que o maior fator de risco para a ocorrência de infecção puerperal é a cesariana, pois a incidência é três a 30 vezes maior, quando comparada ao parto vaginal.

Nascimento et al (2010) apontam em seu estudo que o parto cesariano é alternativa cirúrgica que somente deve ser utilizada em situações nas quais as condições fisiológicas materno-fetais não favorecem o parto vaginal.

\subsubsection{MORTALIDADE MATERNA}

Estudos têm demonstrado que a mortalidade materna está atrelada não somente ao caso clínico, mas a fatores que vão de político-sociais a econômicos e culturais, por não tratar/abordar temas básicos como planejamento familiar, incluindo o cuidado em relação à gravidez de alto risco, sendo os fatores diretos e evitáveis na grande maioria dos casos de MM. (CALDERON; CECATTI; VEJA 2006).

Soarez et al ( 2012) afirmam que o declínio global da RMM tem sido lento, aproximadamente $2,3 \%$ ao ano desde 1990 e que os dados sobre mortalidade materna estão subnotificados.

De acordo com Morse et al (2011), as principais causas de óbito foram doenças hipertensivas, hemorragias, e infecções puerperais, seguidas do aborto. Apontada pelo estudo com o pior indicador, o Norte do Brasil apresenta taxa de RMM $337 / 100.000$ NV. Ainda de acordo com o estudo, a taxa de RMM na região Sudeste fica abaixo da taxa Brasileira fato que se justifica por se tratar de uma região bastante desenvolvida.

As principais causas dos óbitos maternos no Brasil são: outras doenças da mãe que complicam a gravidez, o parto e o puerpério (17,10\%); eclampsia $(11,88 \%)$; hipertensão gestacional com proteinúria significativa $(6,22 \%)$; hemorragia pós-parto $(5,86 \%)$; infecção puerperal $(5,18 \%)$; descolamento prematuro de placenta $(4,28 \%)$. Destaca-se a redução de hemorragias em 19,14\% e infecção puerperal com redução de $9,82 \%$ se comparadas com estudos realizados com dados até o ano 2000 (FERRAZ; BORDIGNON, 2012). 
Segundo Szwarcwald et al (2014), do número total de casos de mortalidade materna informados ao Sistema de Informação de Mortalidade, no período de 2009-2011, somente $55,8 \%$ foram investigados. O mesmo estudo aponta as regiões brasileiras com os maiores índices de investigação, sendo que em primeiro lugar vem a Região Sul (57,6\%); seguida da Região Sudeste (57,3\%); Região Nordeste (55,8\%), Centrooeste $(52,4 \%)$ e por último a Região Norte com $47,6 \%$, que representa menos da metade do total de casos.

Troncon et al (2013) conduziram um estudo de mortalidade materna em um centro de referência do sudeste do Brasil e segundo os autores 39,1\% de MM são de mulheres na faixa etária de 20-29 anos, mais da metade $(56,5 \%)$ não declaram raça e foram classificadas como ignoradas, o mesmo aconteceu com estado civil apontando $(62,3 \%)$.

Dentre os casos de MM, 99\% são registrados em países em desenvolvimento, apenas $1 \%$ em países desenvolvidos, observa-se ainda a tamanha diferença na razão de MM em países desenvolvidos de 14 mortes/100.000NV enquanto que países da América Latina esta razão sobe para 85 mortes/100.000NV. O autor confirma que a maior parte das mortes maternas poderia ser evitada se medidas de prevenção fossem adotadas antes, durante e depois da gestação (VIANA; NOVAES; CALDERON, 2011).

Souza (2013) evidencia que 2015 é o ano que em se realiza a avaliação final dos progressos em relação aos "Objetivos de Desenvolvimento do Milênio" e que mesmo com avanços demonstrados a nível mundial, nacional e estadual, a MM continua a ser uma tragédia global e essa informação torna se mais relevante por se tratar muitas vezes de causas evitáveis.

\section{CONSIDERAÇÕES FINAIS}

A partir da discussão dos resultados, verificou-se que o elevado percentual de cesarianas como importante causa para ocorrência de infecção puerperal e que estes altos índices de cesarianas estão ligados principalmente a fatores socioeconômicos e não a fatores fisiológicos maternos ou fetais. 
Os achados descritos indicam a necessidade de haver transformações que abranjam a efetividade do planejamento familiar, assistência pré-natal adequada, segundo preconiza a Organização Mundial da Saúde, bem como redução do número de cesarianas como forma de evitar complicações pós-parto dentre elas infecção puerperal que é a segunda causa de mortalidade materna. As transformações devem ir além das ações de saúde envolvendo maior eficiência pelos órgãos executores das políticas de saúde no sentido de melhorar o monitoramento das ações visto somente cerca da metade dos casos notificados são investigados, também há deficiências relacionadas às subnotificações, sendo importante ainda fomentar a atuação do enfermeiro no sentido de evitar, controlar e reduzir as infecções puerperais, reduzindo assim os índices de mortalidade materna.

\section{REFERÊNCIAS}

ARAÚJO, S. De A. Et al. Choque séptico puerperal por Streptococcus $\beta$ hemolítico e síndrome de Waterhouse-Friderichsen. Revista da Sociedade Brasileira de Medicina Tropical. 2009.

AZAMBUJA EP, PIRES DP, VAZ MRC. Prevenção e controle da infecção hospitalar: as interfaces com o processo de formação do trabalhador. Texto Contexto Enferm; 13(n.esp):79-86, 2004.

BRASIL. Ministério da Saúde. Secretaria de Atenção à Saúde. Departamento de Ações Programáticas Estratégicas. Manual dos comitês de mortalidade materna / Ministério da Saúde, Secretaria de Atenção à Saúde, Departamento de Ações Programáticas Estratégicas. - 3. ed. - Brasília : Editora do Ministério da Saúde, $2007.104 \mathrm{p}$.

BRASIL. Ministério da Saúde. Portaria no 1.459 de 24 de junho de 2011 - Institui no âmbito do Sistema Único de Saúde - SUS - a Rede Cegonha. Brasília: Ministério da Saúde, 2011.

CALDERON, Iracema de Mattos Paranhos; CECATTI, José Guilherme; VEGA, Carlos Eduardo Pereira. Intervenções benéficas no pré-natal para prevenção da 
mortalidade materna. Rev. Bras. Ginecol. Obstet., Rio de Janeiro, v. 28, n.5, p. 310315, 2006.

COELHO, EAC de et al. Integralidade do Cuidado à Saúde da Mulher: Limites da Prática Profissional. Esc Anna Nery Rev Enfermagem, p. 154-160, Salvador/BA, janmar. 2009.

CRUZ, L. A.; Infecção de ferida operatória após cesariana em um hospital público de Fortaleza, revista eletrônica trimestral de enfermagem, janeiro 2013, no 29.

DUARTE, M. R. et al. Atuação do Enfermeiro no Controle de Infecção Puerperal: Revisão Integrativa. Revista de enfermagem UFPE online. p. 433-41, Recife, fev. 2014.

FALCÃO, Milena Silva. Avaliação da qualidade do pré-natal nas Unidades de Saúde de Palmas-TO. 2011. 11p. Monografia (Bacharel em Enfermagem). Centro Universitário Luterano de Palmas/ Universidade Luterana do Brasil. Palmas Tocantins.

FILHO, E. D. M. et al. Perfil epidemiológico e clínico de pacientes admitidas com diagnóstico de sepse puerperal de origem pélvica em uma UTI obstétrica no Nordeste do Brasil. Rev. Bras. Saúde Matern. Infant.; p. 469-475, Recife/PE, out. / dez., 2010.

FERRAZ, Lucimare; BORDIGNON, Maiara. Mortalidade materna no Brasil: uma realidade que precisa melhorar. Revista Baiana de Saúde Pública v.36, n.2, p.527538 . abr./jun. 2012.

GOIS, K. F. et al. Infecção puerperal em uma maternidade de referência de Teresina-PI. Anais do Congresso Brasileiro de Enfermagem Neonatal, 2012.

GOMES, A. O.; NEVES, J. B. O enfermeiro na assistência à puérpera na atenção primária à Saúde. Revista Enfermagem Integrada - Ipatinga: Unileste-MG - v. 4, n. 2, 2011. 
GUIMARÃES, E.E.R. de et al. Infecção puerperal sob a ótica da assistência humanizada ao parto em maternidade pública. Rev Latino-am Enfermagem USP online. P. 15-21, julho-agosto, 2007.

MARTINS FILHO, Euclides Dias et al . Perfil epidemiológico e clínico de pacientes admitidas com diagnóstico de sepse puerperal de origem pélvica em uma UTI obstétrica no Nordeste do Brasil. Rev. Bras. Saude Mater. Infant., Recife , v. 10, n. 4, p. 469-475, Dec. 2010.

MORSE, M. L. et. al. Mortalidade Materna no Brasil: o que mostra a produção científica nos últimos $\mathbf{3 0}$ anos? Caderno Saúde Pública, Rio de Janeiro, 27(4):623638; abr, 2011.

NASCIMENTO ER et al. Assistência pré-natal em Salvador. Rev. Bras. Saúde Matern. Infant., Recife, 7 (2): 191-197, abr. / jun., 2007.

NOMURA, Roseli Mieko Yamamoto; ALVES, Eliane Aparecida; ZUGAIB, Marcelo. Complicações maternas associadas ao tipo de parto em hospital universitário. Rev. Saúde Pública, vol.38 n.1 São Paulo Fev. 2004.

OLIVEIRA R.; MARUYAMA S. A. T. Controle de infecção hospitalar: histórico e papel do estado. Rev. Eletr. Enf. 2008;10(3):775-83.

SOARES VMN, SOUZA KV, AZEVEDO EMM, POSSEBON CR, MARQUES FF. Causas de mortalidade materna segundo níveis de complexidade hospitalar. Rev Bras Ginecol Obstet.; 34(12):536-43, 2012.

SOARES VMN, MARTINS AL. Comitês de Mortalidade Materna no PR. Rev. Bras. Saúde Matern. Infant., Recife, 6 (4): 453-460, out. / dez., 2006

SOUZA, J. P. Mortalidade materna e desenvolvimento: a transição obstétrica no Brasil, Revista Brasileira de Ginecologia Obstétrica. 2013.

SZWARCWALD C. L. et. al. Estimação da razão de mortalidade materna no Brasil, 2008-2011, Caderno de Saúde Pública, Rio de Janeiro, 30 Sup:S71-S83, 2014. 
TRONCON JK et al. Mortalidade materna em um centro de referência do Sudeste Brasileiro. Rev Bras Ginecol Obstet., 35(9):388-93, 2013.

VIANA, RC; NOVAES, MRCG; CALDERON, IMP. Mortalidade materna: uma abordagem atualizada. Comum. ciênc. Saúde; 22(sup. Esp. 1):141-152, 2011.

ZIMMERMANN, M. H. et al. Perfil epidemiológico da infecção no trato urinário.

Enviado: Novembro, 2020.

Aprovado: Dezembro, 2020. 